Gut, 1975, 16, 201-204

\title{
Changes in the bidirectional sodium flux across the intestinal mucosa in Crohn's disease
}

\author{
ROBERT ALlAN, D. M. STEINBERG, K. DIXON, AND W. T. COOKE \\ From the Nutritional and Intestinal Unit, and the Department of Clinical Chemistry, The General Hospital \\ Birmingham
}

SUMmARY Bidirectional sodium flux across the intestinal mucosa was measured in a group of 10 patients with Crohn's disease treated in the past by panproctocolectomy with ileostomy and compared with a similarly treated group of 11 patients with ulcerative colitis. All of them were in good health at the time of the study and a recent radiological examination of the small intestine was normal.

A significant reduction in bidirectional sodium flux was found in those patients with Crohn's disease and suggests that the intestinal mucosa is involved to a greater extent than can be judged by radiological appearances alone. This adds weight to the concept that Crohn's disease is a diffuse rather than a focal lesion of the gastrointestinal tract.

Patients treated by panproctocolectomy with ileostomy for Crohn's colitis are more prone to episodes of profuse ileostomy output than a similarly treated group of patients with ulcerative colitis, even though they are otherwise in good health with no radiological evidence of recurrent disease in the small bowel (Steinberg, 1974). These episodes are similar, though not in volume, to the massive fluid loss from the intestinal tract in cholera where a reduction of bidirectional sodium flux and net loss of sodium into the intestinal lumen has been demonstrated (Love, Phillips, Rohde, and Veall, 1972).

We have measured the bidirectional sodium flux and net sodium absorption in a group of patients with Crohn's disease and a control group of patients with ulcerative colitis to examine whether there were objective differences in the transport of sodium across the intestinal mucosa. All of them were in good health at the time of the study with normal radiological appearances of the small bowel.

\section{Patients and Methods}

Ten patients with Crohn's disease and 11 patients with ulcerative colitis were studied. The clinical, radiological, and pathological criteria for distinguishing ulcerative colitis and Crohn's disease are identical to those of Lockhart-Mummery and

Received for publication 22 January 1978.
Morson (1960 and 1964) and Lindner, Marshak, Wolf, and Janowitz (1963). All of them had been treated previously by panproctocolectomy and ileostomy with a mean interval of 7.8 (range 1-15) years between surgery and the time of the study in the Crohn's group and 6.9 (range 1-15) years in those with ulcerative colitis. No small bowel resection was undertaken in any of the patients with ulcerative colitis. Nine of the 10 patients with Crohn's disease had resections including the distal ileum at the time of colectomy when all macroscopically involved bowel was removed. The only criteria for including patients in the study was their consenting to take part after it had been discussed with them during their routine review visits. The patients with Crohn's disease were not selected because they were particularly prone to episodes of profuse ileostomy output though four patients did average two or more such episodes per year. They were not studied during an acute episode. None of the patients with ulcerative colitis were prone to episodes of profuse ileostomy output. All patients were in good health at the time of the study and a recent barium meal and follow-through examination had shown no abnormality. The study was approved by the Research and Ethical Committee of the United Birmingham Hospitals.

Intestinal perfusion techniques to calculate unidirectional sodium flux are well established (Mitchell and Neptune, 1965; Love and Phillips, 
$1965)$ and methods are now available to measure bidirectional sodium flux by the simultaneous administration of two isotopes, one given orally and the other intravenously. A single isotope technique for measuring bidirectional sodium flux has recently been introduced and validated by a comparison with the more conventional double isotope technique (Love, Rohde, Abrams, and Veall, 1973) and was therefore used in this study.

The patients were fasted for four hours and a nasogastric tube was passed and positioned in the antrum. A temporary ileostomy bag was fitted over the stoma and connected to a volume metre for collection of the ileostomy output. Hartmann's solution (sodium $154 \mathrm{~m}$-equiv/l) was infused via the nasogastric tube at a rate of $33 \mathrm{ml}$ per minute for one hour when an ileostomy output of 20 to $40 \mathrm{ml}$ per minute was established. The volume of ileostomy output collected during the first hour of the study was measured and a sample was taken for background radioisotope counting.

Once the steady flow rate had been established exactly $4 \mu \mathrm{C}$ of ${ }^{22} \mathrm{Na}$ in $20 \mathrm{ml}$ of Hartmann's solution and $5 \mathrm{ml}$ of a $1 \%$ solution of bromsulphthalein was given as a bolus via the nasogastric tube. The infusion of Hartmann's solution was continued at the same rate for a further hour and the ileostomy output collected and measured in four 15-minute aliquots. The bromsulphthalein marker had been cleared from the ileostomy output in all patients before the end of this second hour. A final sample of ileostomy output was taken immediately after this time to measure the level of radioactivity. This represents the concentration of ${ }^{22} \mathrm{Na}$ which has been absorbed and resecreted from the plasma into the intestinal lumen, which is subtracted from the
${ }^{22} \mathrm{Na}$ in the ileostomy output collected during the second hour of the study to give the corrected dose of ${ }^{22} \mathrm{Na}$ recovered and thus the fraction of ${ }^{22} \mathrm{Na}$ absorbed. The ${ }^{22} \mathrm{Na}$ in each specimen was measured in a liquid scintillation counter and the radioactivity was compared with an accurate 1 in 500 dilution of the administered dose.

Love et al (1973) found that this technique underestimated the stool recovery of ${ }^{22} \mathrm{Na}$ by an average of $1.3 \%$ and applied this as a correction factor. In our study the stool recovery of ${ }^{22} \mathrm{Na}$ lay in the range of $37-76 \%$ of the administered dose. Since their model was not entirely comparable to our experimental situation and since the correction is small it was not applied in our study in calculating sodium fluxes.

\section{Calculation of Results}

The bidirectional sodium fluxes were calculated in accordance with the formulae of Love et al (1973):

$$
F_{P L}=F_{S}(1-\theta)-F_{i}
$$$$
F_{L P}=\theta\left(F_{i}+F_{P L}\right)
$$

where $F_{P L}$ is the plasma-to-lumen flux, $F_{L P}$ is the lumen-to-plasma flux, $F_{S}$ is the ileostomy output, and $F_{i}$ is the infusion rate. Each variable is quantified in units of mequiv/min. The fraction of ${ }^{22} \mathrm{Na}$ absorbed is $\theta$.

\section{Results}

The mean ileostomy output in the first hour of the study was significantly greater in patients with Crohn's disease than in those with ulcerative colitis. The difference between the mean ileostomy outputs in the second hour was not significant (table I).

\begin{tabular}{llll}
\hline & \begin{tabular}{l} 
Mean Ileostomy Output $(l)$ \\
\cline { 2 - 4 }
\end{tabular} & $\begin{array}{l}\text { Crohn's Disease } \\
(10 \text { Patients })\end{array}$ & $\begin{array}{l}\text { Ulcerative Colitis } \\
\text { (11 Patients) }\end{array}$ \\
\hline First hour & $1.3 \pm 0.29$ & $0.90 \pm 0.31$ & P $=0.05$ \\
Second hour & $1.72 \pm 0.24$ & $1.65 \pm 0.39$ & P $=0.05$ NS \\
\hline
\end{tabular}

Table I Mean ileostomy output during the study in Crohn's disease and ulcerative colitis. ${ }^{1}$

IInfusion rate 1.98 litres/hour

\begin{tabular}{|c|c|c|c|}
\hline & \multicolumn{2}{|c|}{ Sodium Flux (m-equiv of sodium per minute) } & \multirow{2}{*}{ Significance } \\
\hline & $\begin{array}{l}\text { Crohn's Disease } \\
\text { (10 Patients) }\end{array}$ & $\begin{array}{l}\text { Ulcerative Colitis } \\
\text { (11 Patients) }\end{array}$ & \\
\hline $\begin{array}{l}\text { Mean } F_{L P} \\
\text { Mean } F_{P L} \\
\text { Mean net absorption } \\
\left(F_{L P}-F_{P L}\right)\end{array}$ & $\begin{array}{l}3.30 \pm 1.57 \\
2.30 \pm 1.30 \\
1.01 \pm 0.84\end{array}$ & $\begin{array}{l}6.15 \pm 1.96 \\
4.81 \pm 1.88 \\
1.34 \pm 0.87\end{array}$ & $\begin{array}{l}\mathbf{P}=0.001 \\
\mathbf{P}=0.001 \\
\mathbf{P}=0.05 \mathrm{NS}\end{array}$ \\
\hline
\end{tabular}

Table II Sodium flux in Crohn's disease and ulcerative colitis 


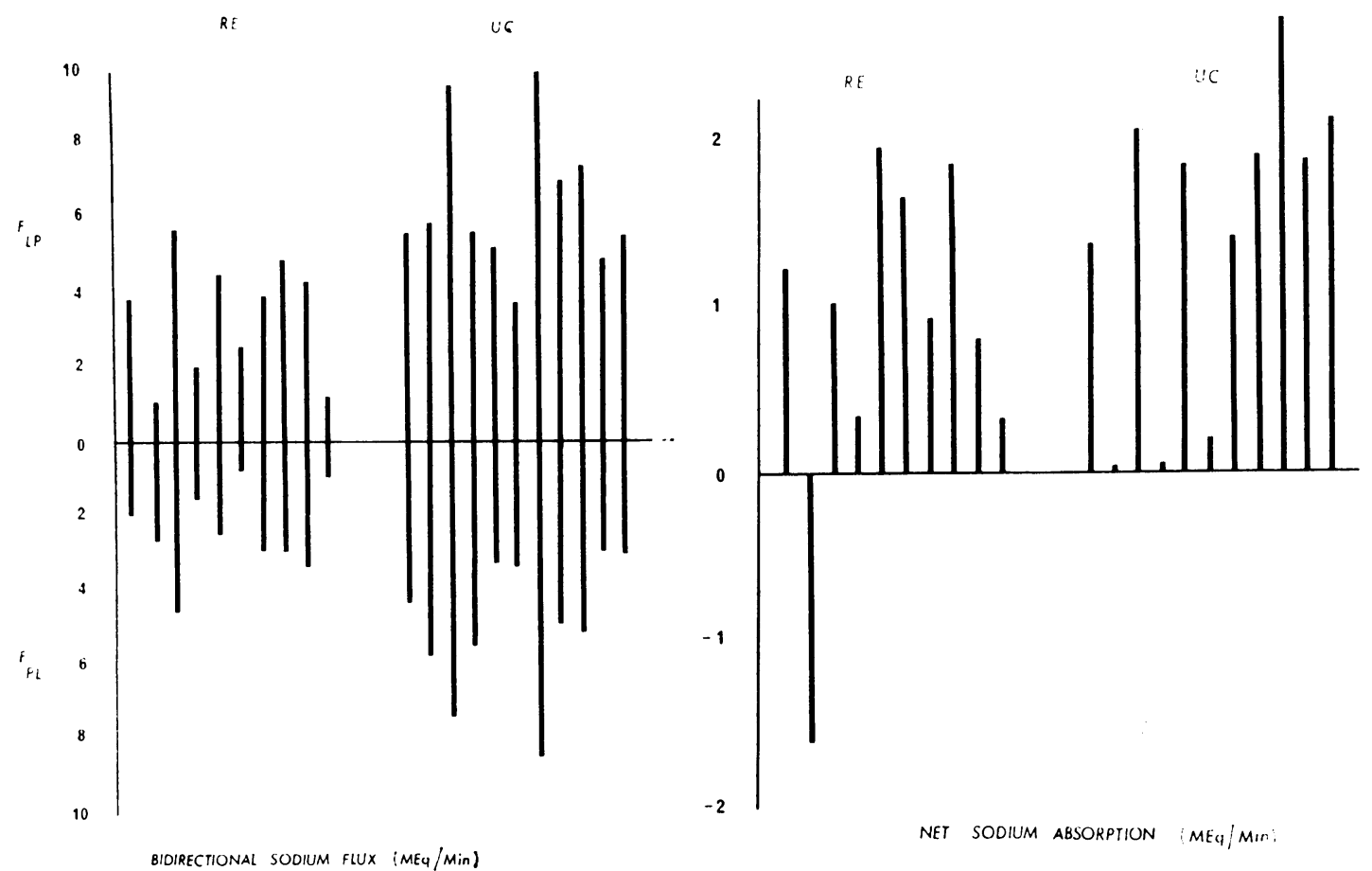

Fig 1

Fig 2

Fig 1 Sodium flux (milliequivalents/minute) across the intestinal mucosa from lumen to plasma (FLP) and from plasma to lumen (FPL) in Crohn's disease (RE) and ulcerative colitis (UC).

Fig 2 Net sodium absorption (milliequivalents/minute) across the intestinal mucosc in Crohn's disease (RE) and ulcerative colitis $(U C)$.

The mean urine output during the two hours of the study was $0 \cdot 15 \pm 0.25$ litres in the Crohn's group compared with $0.72 \pm 0.59$ litres in the ulcerative colitis group $(P<0.05)$.

The bidirectional sodium flux in the individual patient is shown in figure 1 . The mean sodium flux both from lumen to plasma and from plasma to

\begin{tabular}{llll}
\hline $\begin{array}{l}\text { Length of Ileum } \\
\text { Resected }(\mathrm{cm})\end{array}$ & $F_{\mathrm{PL}}$ & $F_{\mathrm{LP}}$ & $\begin{array}{l}\text { Net Absorption } \\
(\text { m-equiv/min })\end{array}$ \\
\hline 0 & 0.9 & 1.25 & 0.35 \\
4 & 3.43 & 4.25 & 0.82 \\
10 & 2.65 & 1.04 & -1.61 \\
22 & 4.63 & 5.66 & 1.03 \\
30 & 3.02 & 4.86 & 1.84 \\
35 & 2.50 & 4.43 & 1.97 \\
38 & 2.0 & 3.18 & 1.18 \\
54 & 0.83 & 2.5 & 1.67 \\
75 & 2.97 & 3.86 & 0.89 \\
80 & 1.61 & 1.96 & 0.35 \\
\hline
\end{tabular}

Table III Sodium flux from plasma to lumen $\left(F_{\mathrm{PL}}\right)$ from lumen to plasma $\left(F_{\mathrm{LP}}\right)$ and net sodium absorption in patients with Crohn's disease ranked according to the length of ileum resected lumen was significantly reduced in patients with Crohn's disease. The mean net absorption of sodium was lower in the group with Crohn's disease but the difference did not reach statistical significance (figure 2 and table II).

The bidirectional sodium flux and the net absorption of sodium in patients with Crohn's disease were independent of the length of distal ileum resected (table III).

\section{Discussion}

We have used a slower infusion rate $(33 \mathrm{ml}$ per minute) than that recommended by Love et al (1973) of $75 \mathrm{ml}$ per minute because they were perfusing both small and large bowel, whereas our study was confined to perfusion of the small bowel alone. This alteration in technique does not affect our findings because we used the same method throughout the study and we were chiefly concerned with differences between the two groups rather than with individual results. 
The difference in bidirectional sodium flux between patients with Crohn's disease and ulcerative colitis was foreshadowed by the higher ileostomy output in the first hour of the study and the reduction in total urine output in patients with Crohn's disease during the experiment. This suggested that absorption of the infused fluid was impaired in the small intestine of patients with Crohn's disease.

The reduction of bidirectional sodium flux in patients with Crohn's disease was not related to the length of ileum resected, probably because sodium movement across the intestinal mucosa occurs principally in the duodenum and upper jejunum (Banwell, Pierce, Mitra, Brigham, Caranasos, Keimowitz, Fedson, Thomas, Gorbach, Sack, and Mondal, 1970; Love et al, 1972).

There was no significant difference in the net absorption of sodium in the two groups, possibly because no patient was studied during an episode of profuse ileostomy output. A study of patients with Crohn's disease during such episodes would be of value to determine whether the reduction in bidirectional sodium flux is associated with a net loss of sodium as well. Certainly the only patient who had a net loss of sodium when this study was done experienced the most severe and frequent episodes of profuse ileostomy output.

The reduction in bidirectional sodium flux across the intestinal mucosa in Crohn's disease where there is no radiological abnormality of the small intestine suggests that the gut may be more extensively involved than can be gauged by radiological appearances alone. The use of the term 'recurrent disease' after resection may be erroneous, and 'reactivation' of established disease a more likely explanation. These findings add weight to the concept that Crohn's disease is a diffuse rather than a focal lesion of the gastrointestinal tract which may be important when considering aetiological factors in the disease process.

\section{References}

Banwell, J.G., Pierce, N. F., Mitra, R. C., Brigham, K.L., Caranasos, G. J., Keimowitz, R. I., Fedson, D. S., Thomas, J., Gorbach, S. L., Sack, R. B., and Mondal, A. (1970). Intestinal fluid and electrolyte transport in human cholera. J. clin. Invest., 49, 183-195.

Lindner, A. E., Marshak, R. H., Wolf, B. S., and Janowitz, H. D. (1963). Granulomatous coltis: a clinical study. New Engl. J. Med., 269, 379-385.

Lockhart-Mummery, H. E., and Morson, B. C. (1960). Crohn's disease (regional enteritis) of the large intestine and its distinction from ulcerative colitis. Gut, 1, 87.

Lockhart-Mummery, H. E., and Morson, B. C. (1964). Crohn's disease of the large intestine. Gut, 5, 493-509.

Love, A. H. G., and Phillips, R. A. (1965). Gastrointestinal transport of sodium in man. (Abstr.) Fed. Proc., 24, 344.

Love, A. H. G., Phillips, R. A., Rohde, J. E., and Veall, N. (1972). Sodium ion movement across intestinal mucosa in cholera patients. Lancet, 2, 151-153.

Love, A. H. G., Rohde, J. E., Abrams,'M. E., and Veall, N. (1973), The measurement of bidirectional sodium flux across the intestinal wall in man using whole gut perfusion. Clin. Sci., 44, 267-278.

Mitchell, T. G., and Neptune, E. M., Jr. (1965). Sodium transport measurement in monkey small intestine. (Abstr.) Fed. Proc., 24, 344.

Steinberg, D. M. (1974). The place of surgery in Crohn's colitis. ChM Thesis, University of Birmingham. 